\title{
The public face or Psychological and legal complexities in plastic ophthalmic surgery
}

\author{
VIRGINIA LUBKIN \\ From the Department of Ophthalmology, Mount Sinai School of Medicine, New York
}

Does plastic surgery lead to psychological complications of sufficient frequency and severity to pose a threat to the patient, the surgeon, and even the surgical outcome? The literature on the subject, while modest in amount, bristles with cautionary statements about the heavy load of psychopathology imbuing the patient population who affront nature, religion, and common sense by demanding a surgical revision of its body-image. Curiously enough, most of these papers end with the observation that the actual incidence of postoperative psychiatric collapse is surprisingly low; and even that cosmetic plastic surgery, carefully planned, can at times be recommended as part of an overall psychotherapeutic regimen for neurotics and psychotics (Linn and Goldman, 1949).

\section{Motivation of the patient}

The most consistent body of work was carried out under the aegis of Edgerton, who supported a formal series of studies of his surgical patients by psychiatric consultants (Webb, Slaughter, Meyer, and Edgerton, 1965; Jacobson, Edgerton, Meyer, Canter, and Slaughter, 1960; Meyer, Jacobson, Edgerton, and Canter, 1960; and Knorr, Hoopes, and Edgerton, 1968). Meyer (1964) noted that at least one-third of 157 patients who requested the services of a plastic surgeon were in need of psychiatric help.

Investigation of 106 patients seeking meloplasty (a group comparable with those seeking blepharoplasty) revealed the following findings. Very few were men, and these were much more likely to be mentally disturbed. Of the women, those who were under 40 years tended to be sicker emotionally; those between 40 and 50 years seemed largely to be driven by vocational needs to look young; those over 50 years were usually reacting constructively to a severe personal loss, such as recent widowhood. What is striking was the almost universal satisfaction with the operative result-on several occasions far beyond that of the surgeon. Altogether 86 per cent were eminently delighted-especially in the older groups. These patients would correspond

Address for reprints: V. Lubkin, MD, FAcs, 4I Park Avenue, New York, NY roor6, USA well with our blepharoplasty candidates, and are probably the motivational equivalents.

The study compared non-cosmetic elective surgery controls with rhytidectomy patients (Webb and others, 1965). The psychological profile of the cosmetic group was consistent enough for the psychologist to identify seven out of eight. 'The particular pattern of lack of intimacy and of satisfying interpersonal relationship and the importance of personal achievement and independence, in combination with a dread of ageing, is striking in these patients'.

Findings in the non-operated group, who had come in for consultation about the procedure, were even more interesting. Of the 42 , half had been counselled against surgery by the surgeon and the psychiatrist for physical or psychological reasons. This non-operated group more frequently reported past psychiatric treatment, and were significantly younger at the time they requested surgery.

The status of the man seeking cosmetic surgery is controversial. Until ro years ago, he was certainly breasting the cultural current. Thus, Edgerton's group (Jacobson and others, 1960) evaluating men requesting aesthetic surgery for small defects showed a large incidence of serious psychopathology. Of 31 examined psychiatrically, 17 were diagnosed as psychotic or neurotic, and the remainder were labelled as cases of personality trait disorders. By contrast, only 48 of the group of 72 women undergoing 'face-lifts' merited a psychiatric diagnosis. This distribution is, of course, consonant with our ancient cultural patterns in which woman is dependent upon her physical seductivenęs, while the 'normal man' can eschew male beauty in favour of masculine ruggedness.

Substantiating this point with inverse evidence, Hill and Silver (1950) gave details of a number of men in whom unconscious homosexual needs compelled the retailoring of a nose too grossly reminiscent of a painfully masculine father. The nose is, of course, an ancient associate of the penis in the roster of symbolism.

A further corollary in this behavioural pattern is the extraordinary readiness of frank young male homosexuals to undergo very early facial plastic surgery. Driven by narcissism, as well as 
by a desperate need to retain seductiveness in their shifting society, men in their early thirties are to be seen anxiously scrutinizing the minimal lid bag and the non-existent jowl.

Dysmorphophobia is the perhaps over elegant term applied to certain somatic delusions. As noted by Hay (1970a), it describes 'obsessive preoccupation with a cosmetic defect when that organ or appearance is, to the observer, unquestionably within the normal range and not displeasing'. Any external contour may be the targetmouth, smile, penis, breasts, lines under eyes, buttocks, arms, legs, eyebrows, etc. Nichtern (1974) pointed out that, in those patients in whom the complaint had some degree of reality, careful psychiatric evaluation would contraindicate surgery during an ascending storm of psychopathology, only to encourage it later as part of the rehabilitation of the patient.

Since such patients are likely to present themselves to the plastic surgeon without any intimation of mental disease, he must in his own defence incorporate certain criteria into his automatic thinking. Druss, Symonds, and Crikelair (1971) point out that, when the deformity is slight and the patient expresses startlingly disproportionate disgust and aversion, one should be wary of surgery. When the candidate is convinced that all life's failures are attributable to his unique defect, there is cause for caution. In attempting to determine how realistic are the patient's expectations, it is useful to ask him to describe the lesion in his own words: he may then launch into telltale exaggeration and add bizarre touches. He may claim that some innocent keratosis swells enormously, turns purple, and produces knife-like pains. Since his expectations from the surgery manifestly go far beyond what the most skilful surgeon can provide, the resentment at what seems to the outsider to be an anatomically perfect result boils over into anger.

It would, however, be cruel to assume that every patient with a minor defect is cursed with serious psychopathology merely because he would like it remedied. A meticulous study of the psychological features of 45 candidates for nasal plastics was made by Hay (1970b). It was his conclusion that, barring the occasional dysmorphophobic schizophrenic, the self-estimate of this plastic surgical group as deformed people was confirmed by the ratings of objective observers. The patients were more conscious of being disfigured than was estimated by the observers, but not inordinately so. The feeling was that the criterion for endorsing surgery should be 'the degree to which the patient's overall appreciation of the possibilities and limitations of the procedure are consonant with reality, no matter how disturbed he or she may otherwise be'. If this postulate is accepted the degree of deformity is not to be considered, as early painful conditioning or the special demands of cultures alien to our own may reinforce the need in a manner beyond our awareness.

We live increasingly in a pluralistic world culture. For example, compare the extraordinary photographs culled with great effort by Rees and Wood-Smith (1973) to stun the onlooker with standards of bodily beauty, from the nose-rod of the Sepik Valley tribesman to the lips of the Ubangi to the earplugs, crossed eyes, and flattened heads of the Maya. The keloid that is a torment in New York City becomes a cutaneous art form in central Africa. The time may come when ophthalmic plastic surgeons will have to devise a procedure to eliminate the lid fold and orientalize the western upper lid.

We must recognize that the definition of deformity is not simple, is not necessarily our own, and that what is unimportant to us may not be to others. On the other hand, one must beware of the 'concave mirror syndrome': the patient who uses magnification to find every wrinkle preoperatively will also use it postoperatively to agonize over every normal scar. It is vital to be sure that doctor and patient see the same defect (Macgregor, 1974), and to be explicit in understanding what the patient wishes and what the doctor plans. Meyer (1964) said what is desired is the 'surgical correction of the perceived body-image'.

\section{POSTOPERATIVE PERIOD}

A transient acute depression on about the third day is not uncommon. More dangerous symptoms are feelings of depersonalization, stated as feeling 'not real', 'wooden', or 'not really here'. One must remember that, after plastic surgery, an acute change in self-image is taking place. The patient is suddenly confronted with the full weight of the symbolic value of the change, with the death and rebirth fantasy, with uncertainty as to the result, with the anticlimax of oedema, ecchymosis, sutures, and scars, and with the accumulated hopes and fears of decades. Attentiveness and solicitude by the surgeon at this juncture may be critical.

THE POLYSURGICAL PATIENT, OR

'THE MÜNCHAUSEN SYNDROME'

Asher (195I) in the Lancet used the name of the extravagant story-telling traveller, Baron Hieronymus Karl Friedrich Münchausen, to describe a type of 'perennial, peregrinating, problem patient' who arrives with fantastic but convincing complaints and a body bedizened with surgical scars. $\mathrm{He}$ categorizes them as:

I. Abdominal type (Laparotomophilia migrans) 
2. Bleeding type (Haemorrhagica histrionica)

3. Neurological type (Neurologica diabolica), to which we may add

4. Mania chirurgico-plastica.

Wahl and Golden (1966), analysing the psychodynamics of the polysurgical patient, pointed out that a repetitive behaviour pattern persists only because it is rewarded. This leaves one to speculate about the nature of the gratification gleaned from the pain, the anxieties, and the proximity to death involved in the surgical experience. The gains from psychiatrically-determined behaviour are usually described as primary and secondary. Primary gains, as the authors put it, subserve an unconscious need originating in the primitive childish irrational part of the mind, and they represent efforts to resolve, symbolically, some conflict-such as guilt over unacceptable sexual feelings. Secondary gains, as the words imply, are subsidiary advantages which accrue to the patient as a consequence of being ill-such as the fulfilment of dependency needs, the permission to withdraw from areas of conflict, 'failing with honour', and the pleasures of special attention.

Study of the 16 patients reveals a number of common characteristics. There is a kind of magical thinking, which, in the unconscious, equates the childhood guilt with some anatomical focus. After its surgical removal, there is euphoria. I am reminded of the universal acclaim accorded to missionary doctors during my visit to the French Cameroon when the ovarian dermoid containing hair and teeth was displayed to the assembled multitude as proof that western doctors could indeed, by surgery, remove the witch known to everyone as the cause of the disease.

Another primary gain is the unconscious concept of the ancient rite of the 'bloody sacrifice'. Furthermore, as the majority of these patients were longdeprived women with deep sexual frustrations, the operations often represented a copulatory act, with the surgeon an erotic figure and the patient guiltless because asleep. Finally, fear of death and fantasies of rebirth played a large role.

Needless to say, since the original emotional problem remains unresolved, the brief elation after surgery departs, and the patient slowly builds up to the next dramatic episode. They seem to be heavily resistant to suggestions for psychotherapy.

These patients tend to be seductive and flattering, quite sure that this particular doctor is the one who can solve profound surgical problems no one has succeeded with before.

THE MOTIVATION OF THE SURGEON

If this paper has seemed freighted with warning, it is because the surgical impulse, the 'furor operandi', is so powerful. Surgeons tend to be notoriously unaware of the psyche of the patient, and to 'stonewall it out' on the purely organic basis. Various studies of the surgical personality (Meyer, 1967) indicate that much of this behaviour is an understandable defence against chronic exposure to maximal human needs and fears, and is undertaken to permit a saving degree of objectivity. But the punishment for this medical naiveté can be bitter, not only in the endless torment by the unhappy patient, but also in the further unpleasantness of law suits.

The surgeon brings to the relationship a meritorious desire to improve the patient-sometimes so intense as to be labelled the 'Pygmalion complex'. But he must not forget that the patient brings to him an extensive hierarchy of needs. Many patients date their improvement from their first visit to the consulting room, namely, the first time that the deformity was accepted by an authority, and a process begun to correct it (Meyer, 1964).

The surgeon should also be cognizant of the patient's powerful capacity to manipulate him. Somewhere in the house surgeon's training, time should be found for that minimum of psychological training that would make the doctor simultaneously aware of his own weak points and of the probable patterns of patient personality with which they can interdigitate. A number of case histories sent me by several senior consultants illustrate that painful experience has taught them well. With a modicum of psychiatric exposure, our younger surgeons may succeed in avoiding unnecessary trauma to themselves and to their patients.

It is not only elective cosmetic surgery that is subject to psychological pitfalls. Numerous other problems exist.

\section{Amputation depression}

The loss of an eye is an amputation, and it is mourned as a death. Apart from the obvious problems of the final cosmetic excellence, there is a consideration which, for some people, is intolerable - the defective body-image. One should not lightly propose the removal of a blind eye, or even an unsightly blind eye, without having some sort of communication with the inner, unspoken sense of self of the patient. The mysterious phantom limb syndrome (Compton, 1973) has undoubted psychogenic components. I am reminded of a young man who had had one of the first of the new buckling procedures for retinal detachment some I 5 years ago. The enthusiasm of the surgeon was so great that the patient was given no intimation that complications were conceivable, and he took it all very lightly-until re-operation, infection, and chronic uveitis destroyed ocular function. Finally, enucleation was necessary for chronic pain. After 
loss of the eye, and despite a perfectly quiet socket, there persisted for a full decade a burning discomfort in the socket, the brow, and the head, very slowly wearing away with the passage of time. There was little explanation possible, other than the phantom pain syndrome.

Even with a good level of psychiatric awareness, it may be difficult to avoid disaster. There was the recent case of the middle-aged lady with the painful bullous keratopathy in an eye blind for 20 years. Enucleation having been advised, she came flying back to her favourite ophthalmologist who, well trained in ophthalmic plastics, decided to do the best of all possible procedures, an evisceration with an expandable Soll implant. The result, medically, could not be bettered. The patient, however, slid gradually into a state of agitated depression with paranoid overtones, alternately berating and adoring the surgeon. She spent hours daily inspecting the socket for drainage of its contents through fancied leaks, isolated herself in her house, and could not be brought to psychotherapy.

In certain people, one would be well advised to leave the eye in situ, providing that there are no medical indications for removal. But how does one predict reactive breakdown after enucleation? Computerized personality profiles are not available, and if they were they would probably betray us; it is not customary to demand the Rorschach and thematic apperception tests from our patients, although there is much to recommend such an approach. Clearly, not all patients are equally devastated by mutilating procedures. It is chiefly when the physical alteration removes or compromises a specific organ vitally concerned in the patient's particular psychiatric adaptation, that he collapses. Thus, enucleation of the eye becomes insupportable in women for whom there is no substitute for physical beauty, and whose selfcontempt and self-hatred after mutilation are obsessive. Perhaps the best rule is to avoid persuasion, and to leave the patient the option of deciding on surgery when the pain becomes intolerable.

The medical community, preoccupied with motion of the prosthesis and depth of the superior sulcus, may forget (if it ever knew) not only that the single or paired eye has deep specific unconscious symbolic meaning, but also that any organ loss is a deep threat to the 'wholeness' of man, and that in men the wholeness equates with virility (Compton, 1973). A young Latin-American of 24, extremely handsome and imbued with legitimate 'machismo', sustained an industrial burn which destroyed the adjacent halves of both lids of the left eye and, finally, the globe. During the endless reconstructive surgery, which he tolerated with infinite patience and grace, never did he mention the agonies of his guilt and shame. Instead, in full knowledge of the dangers of uniocularity, he went back to his beloved racing cars, and also plunged into an ostentatious and grossly inappropriate love affair. Fortunately, both these semi-suicidal reaction patterns did not succeed in killing him, and, having proved himself to himself, he returned to a less braggart existence.

The ironic fact is that, more often than not, the chronic complainer or the 'difficult' patient does, indeed, get short shrift (Caine, 1973). Take, for example, the matter of the enucleation prosthesis. Dealing with the difficult patient rapidly becomes so onerous for all concerned that, when the surgeon finally pulls together his courage and his conscience (on some chance day when his ego-support level is high), he will undoubtedly find that a poor job has indeed been done. Swanson (1967) observes that patients with psychiatric problems show a higher incidence of true surgical complications, such as wound infection, thrombophlebitis, ileus, pulmonary infection, etc. An increased level of postoperative caution is clearly indicated.

Describing his experience as liaison psychiatrist to a general surgical service, Rosen (1950) found four postoperative patients whom he was called to see because of the pathological extent of the bland denial of the affront of amputation, colostomy, etc. This reaction was soon followed by acute depression. His interpretation was that all the affective machinery of active mastery of the environment, learned early in childhood, had broken down before the unmeetable catastrophe. Regressing to infantile dependency, the victim clung to the current parent figure-the surgeon. And now, the latter, himself human, was faced in a curious way with the guilt of his inevitable inadequacy to the miraculous image of the healerpriest. While, in general, the good surgeon understands and assumes these burdens and may handle them well, there are more complex situations in which the help of the psychiatrist may be essential.

Specialists in rehabilitation are intensely aware of these considerations (Miller, 1972). Watching the convalescent patient closely from the earliest postoperative days, they start immediately, as indicated, with anti-depressants, tranquillizers, group therapy, individual therapy. They proceed prophylactically. We should do the same.

\section{Cancer delay}

The ophthalmic plastic surgeon is all too frequently confronted by the appalling sight of the patient who has allowed a cancerous process to eat away his eyelids. Why do they wait?

A relevant article is that of Hackett, Cassem, and Raker (1973), who analysed the length of elapsed time in 563 patients. A comparison of the findings with those of Simmons and Daland (1924) in a 
pioneering study is disconcerting. The delay graph after some 50 years of public propaganda is not strikingly different. About 30 per cent of people consult a physician within the first 4 weeks after observing a telltale symptom. At the other end of the curve (see Figure) occurs an asymptote which indicates that 10-20 per cent never even bother to see a doctor throughout the illness.

Those who scorn routine physical examination, should note that the most reliable method of securing rapid medical intervention in cancer turned out to be its discovery in a routine examination.

Worry or fear about cancer in particular and about their health in general did not make the patients seek advice early. In fact, the worriers delayed longer, particularly those who had had some contact with publicity giving dire warnings and describing signs of cancer. Apparently the worrier is convinced that the disease is incurable, and therefore avoids the confrontation with the physician as he is sure that it will merely confirm his terror and will offer no hope.

Even when these subjects felt that 'it runs in the family', they were again more likely not to go for examination, once again regarding the disease as hopeless, because hereditary.

The patients who delayed about cancer also delayed about general symptoms. Interestingly enough, they stated that they were quite aware of delaying. In other words, delay appears to be a conscious and deliberate act performed by many.

As Lawrence (1967) remarked, these mechanisms for the conversion of anxiety into denial make for a 'brave' patient. But denial is a two-edged sword; and the 'good soldier' may be merely the one who is not facing the realities, and who falls apart when they actually arrive.

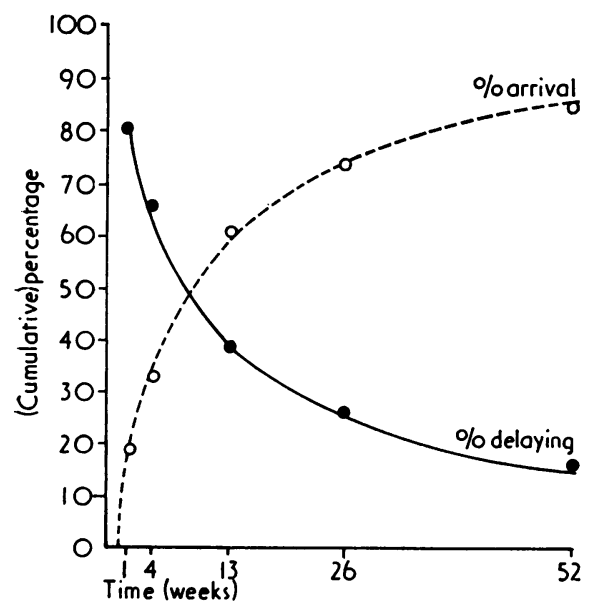

FIGURE Rate at which patients sought advice in the first year after onset of symptoms
The conclusion of the study is that current methods of cancer education by exhortation and warning and information seem ineffective. Progress may begin when long-range strategy starts to investigate in depth the psychology of delay.

\section{Age of surgery in children}

Anxiety is a normal part of the adaptive machinery of man and beast. For every situation, there is an optimal level of anxiety. Ramsay (1972), reporting a survey of preoperative fear in 382 pre-anaesthetic patients, found that 73 per cent admitted to severe fear. Curiously, it made no difference whether the surgery was major or minor. Fear of the anaesthetic outweighed fear of the surgery by $4: 1$. In the youngest group (aged 4-12 years), the percentage of the fear-ridden was 55 per cent; in the oldest (aged 62-82 years), 57 per cent; in the middle (aged 22-62 years) 82 per cent.

This kind of study did not help in the muchdebated problem of the ideal age for elective surgery in children. A computerized bibliographical printout contributed remarkably little data on the subject. A well-known child neuro-psychiatrist (Nichtern, 1974) observed that there are two critical periods in the normal developmental sequence in which the self-image is in a state of flux. These are at the ages of 4 to 6 years (on the earlier side in girls, the later side in boys), and again at pubescence. In the first phase, the child is preoccupied with his definitive differentiation from fusion with the parents or parent-figures. Individuation and separation are taking place. The inner statement and the inner question are, 'I am!' and 'Who am I?'. It is at the same time characteristic that the boundaries of the psychic self-image become co-extensive with the boundaries of the body-image.

This is the age of panic at small cuts and bruises. So-called castration fears are at their maximum, and spread to include all parts of the body. This is the age of sleep problems, the fear of death, the fear of going to sleep lest one should not awake. As it happens, this is also an age of visual preoccupation, of voyeuristic intensity, of visual nightmares ('I see the monster coming to kill me!') threatening bodily destruction. This age is therefore the most vulnerable to assault upon the bodyand surgery is assuredly the maximal assault.

Needless to say, the emotionally healthy child, properly handled, will master the surgical trauma. What is to be remembered is that this age is singularly subject to trauma by precisely what we are imposing. Ironically, elective surgery like ptosis repair seems to be planned time and again for exactly these years, as resolving the cosmetic problem 'just before school'. 
A great deal occurs in the child psyche of which we are not aware. I have seen nightmares go on, postoperatively, for months, and chronic bedwetting start immediately after strabismus surgery. It is all too easy to condition the young organism, and to end with the serious fixation of buried anxiety in somatic areas. After all, this sort of early experience must account for the wealth of eye anxiety that pours so mysteriously over the office in the daily practice of ophthalmology.

One must conclude, therefore, that ocular surgery in the child, other things being equal, is best performed before 4 or after 6 years of age.

Another important point is the need for a dependable parent-figure to accompany the child throughout the hospitalization. There is admittedly some nuisance value in the maternal presence. But, as Dr Nichtern said, one of Freud's greatest contributions was the concept of regression in developmental level as a defence against anxiety. Subjected to any severe enough stress, we will all regress: the child will go back to the early separation anxiety, frightened for the integrity of the self. $\mathrm{He}$ is in desperate need of the parent who first handled these early problems. The 'institutional package' in the children's ward may be highly convenient for the hospital; what matters is the mental health of the child.

A final consideration deals with the cerebral palsied child, the so-called 'organic or braindamaged' individual. Among them, the incidence of ocular symptomatology is of the order of 50 to 60 per cent, including strabismus, nystagmus, amblyopia, and high degrees of myopia. Psychological testing reveals them to be so strikingly immature in their development that their bodyimage (as shown in their Goodenough or human figure-drawing tests) remains for years at the level in which the head-mass is still hugely preponderant. This means that surgical or medical treatment of the organs in the head is full of threat, and should be undertaken with special caution.

\section{Appendix}

\section{LEGAL COMPLICATIONS OF OPHTHALMIC PLASTIC SURGERY}

The threat of the malpractice suit hangs like a pollutant in the air of the consulting room of the cosmetic plastic surgeon. Despite increasing acceptance of the refashioning of the body*, there is usually an unspoken sense of guilty conspiracy underlying the discussion between physician and patient. The Old Testament speaks harshly, 'Vanitas vanitatem, et omnia vanitas!'**,

\footnotetext{
*Although most medical insurance companies have rejected payment for such surgery out of hand, Medicaid lists rhytidectomy openly as available to the underprivileged

**Ecclesiastes, i, 2 and $\mathrm{xii}, 8$
}

and leaves its traces in our thinking. Despite the lack of generosity in these attitudes, they act as a salutary restraint upon indiscreet enthusiasm in both parties.

A well-known New York attorney* who has extensive experience in malpractice cases has contributed a number of comments.

'An 1898 New York decision explains the basic law of malpractice. A doctor has five duties toward his patient: to possess the requisite learning and skill; to exercise due care; to use his best judgement; to keep abreast of the times; and to follow approved methods of treatment.

'As a lawyer, I should point out that the psychology of a client complaining of a doctor is very stark. A client of the lawyer, a former patient of a doctor, is a person disappointed in the treatment rendered and usually traumatized by the medical and hospital bills.

'One of the most immediate problems for the plastic surgeon at present is the question of "consent" and "informed consent". Perhaps the most difficult recent doctrine to plague the medical profession is that of "informed consent". A doctor must make certain matters clear to his patient:

1. He must tell him the nature of his condition;

2. He must tell him the proposed treatment;

3. He must tell him what the alternatives are;

4. He must state the risks and chances of failure of the treatment or lack of treatment;

5. He must state the risks of alternative treatment.***

'Under the use of the "informed consent" approach, which is now the law in New York, you need not prove malpractice or negligence on the part of the doctor. In fact, in a recent New York case, it was decided that the patient need not produce an expert to testify what the doctor should have said to the patient, but that the scope of information given is determined by the general standard of conduct which is reasonable under the circumstances, and the words are not governed by the profession's standards. Furthermore, the New York case holds that it is the surgeon's responsibility to inform the patient of the risks, and not the responsibility of the hospital.

'Now as a practical matter, what do you do about obtaining a proper consent? I have heard of one California surgeon who will not operate on a patient unless the doctor, the patient, the patient's attorney, and a notary sit down and discuss the matter, and a transcript is made and signed. This may be an absurd extreme, but I earnestly suggest that the five elements of an "informed consent" noted above be covered in a consent form for an operation'.

The surgeon, intimidated by these ominous legalisms, faces the dilemma of maintaining his patient's confidence in himself, in the anaesthetic experience, in the probability of cure, in fact, in the general effectiveness of medical therapy-

*Paul S. Edelman, a member of the firm of Kreindler and Kreindler, New York City

* Italics added 
while he is expected, just before surgery, to run down a thorough listing of the chances of shock, of haemorrhage, of infection, of nerve damage, of hypertrophic scars, of post-thrombotic emboli, of falling out of bed, of remaining in bed, of malnutrition from dietetic economies, etc., etc. No physician in his right mind can confront a surgical candidate with a truly foolproof legal document.

It is important to be certain that the patient has indeed heard what has been said in the consulting room, and not his own wishful distortions (Meyer, 1964). One must also be wary of those who regard the surgical procedure as so magical that they never grasp the possibility of pain, of trauma, of scar, etc. An excellent manoeuvre is the presentation at the first visit of a 'letter to the patient', after the manner of Rees and Wood-Smith (1973), that confronts him quite reasonably with the realities of the impending experience.

A fairly good example of an informed consent for a blepharoplasty follows (modified from Baker and Gordon, 1967).

I wish to offer special thanks to Dr Mortimer Ostow, Professor of Psychiatry at the Jewish Theological Seminary, for his interest and patience, without committing him to any errors for which I may be responsible.
I hereby authorize $\operatorname{Dr} . \ldots \ldots \ldots \ldots \ldots \ldots \ldots$ and Dr..................... and/or their associates to perform a surgical operation known as blepharoplasty, commonly known as eyelid plastic, on

$$
\text { Name of patient or 'Myself' }
$$

The procedure named above has been explained to me by the above doctors, and I completely understand the procedure in so far as possible. The following points have been specifically made clear:

a. There are, of course, scars as a result of this surgery. Every effort will be made to conceal or to make them as inconspicuous as possible.

$b$. There may be swelling in the eyelids which will persist for several weeks.

c. There may be discolouration (black and blue) for several weeks as well.

$d$. That no guarantee has been made as to the amount or percentage of improvement either in terms of apparent age or as to the permanency of results.

\section{References}

ASHER, R. (I95 I) Lancet, I, 339

BAKER, T., and GORDON, H. (1967) Plast. reconstr. Surg., 40, 3 I

CAINe, D. (1973) Med. F. Aust., 2, 818

Compton, C. Y. (1 973) Nursing Clin. No. America, 8, 53

DRUSS, R., SYMONDS, F., and CRIKELAIR, G. (I97I) Plast. reconstr. Surg., 37, 246

HACKETT, T., CASSEM, N., and RAKER, J. (1973) New Engl. F. Med., 289, 14

HAY, G. G. (1970a) Brit. F. Psychiat., 116, 399

(1970b) Ibid., 116, 85

HILl, G., and SILVER, A. G. (1950) Psychosom. Med., 12, 345

JACOBSON, W., EDGERTON, M., MEYER, E., CANTER, A., and SlAUGHTER, R. (r960) Plast. reconstr. Surg., 26, 356

KNORR, N., HOOPES, J., and EDGERTON, M. (I 968) Ibid., 4I, 248

LAWRenCe, D. E. (1967) Int. Psychiat. Clin., 4, no. 2

LINN, L., and Goldman, I. B. (1949) Psychosom. Med., II, 307

MACGREGOR, F. C. (1974) 'Transformation and Identity', chap. 7. Quadrangle; New York Times Book Co.,

New York

MEYER, B. c. (1967) Int. Psychiat. Clin., 4, no. 2

MEYer, E. (1964) Psychiatric Aspects of Plastic Surgery, in 'Reconstructive Plastic Surgery', ed. J. M. Converse,

vol. I, p. 365. Saunders, Philadelphia

- Jacobson, W., Edgerton, M., and Canter, A. (1960) Psychosom. Med., 22, i 93

Miller, R. (1972) Proc. nat. Cancer Conf., 7, 855

NICHTERN, S. (1974) Personal communication

RAMSAY, M. (1972) Anesthesia, 27, 396

REES, T., and WOOD-SMITH, D. (I 973) 'Cosmetic Facial Surgery'. Saunders, Philadelphia

Rosen, v. (1950) Psychosom. Med., 12, $35^{\circ}$

SIMMONS, C., and DALAND, E. (1924) Boston med. surg. $\mathcal{F} .$, 190, 15

swanson, D. (1967) Int. Psychiat. Clin., 4, no. 2

WAHL, C., and GOLden, J. (1966) Psychosomatics, 7, 65

WEBb, JR., W. L., SLAUGHTER, R., MEYER, E., and EDgERTON, M. (1965) Psychosom. Med., 27, I83 